\title{
DES ZWEITEN BANDES
}

Des Gegensatzes andere Seite: Entwicklung des Bewratseins der

Gnade $\$ 86-169 \ldots \ldots$. . . . . . . . . . . I

Einleitung $\$ 86-90 \ldots \ldots \ldots$ II

Erster Abschnitt: Von dem Zustande des Christen, sofern er sich der göttlichen Gnade bewußt ist $\oint_{9 \mathrm{I}-112 \ldots} \ldots{ }_{29}$

Einleitung $\$ 91 \ldots \ldots . \ldots$

Erstes Haxpestuck: Von Christo \$92-ros . . . . . . . . 3I

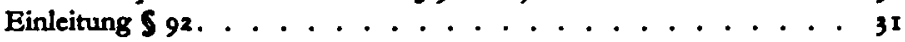

Erstes Lehrstück: Von der Person Christi \$93-99 . . . . . . . 34

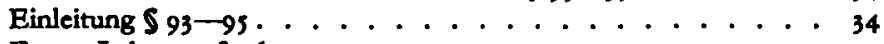

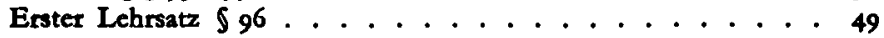

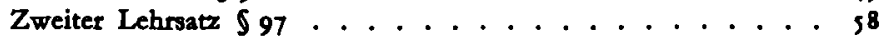

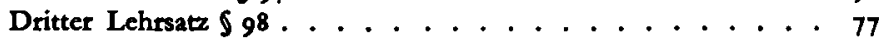

Anhang \$99.................. 82

Zweites Lehrstück: Von dem Geschäft Christi I00-ros . . . 9 90 VI

Einleitung $\$ 100-102 \ldots . . . . . . . .99$

Erster Lehrsatz $\$$ ro3. . . . . . . . . . . . . . . . 108

Zweiter Lehrsatz $\$$ r04 . . . . . . . . . . . . . II8

Dritter Lehrsatz $\oint$ ros . . . . . . . . . . . . 136

Zweites Hauptstuck: Von der Art, wie sich die Gemeinschaft mit der Vollkommenheit und Seligkeit des Erlösers in der einzelnen

Seele ausdrückt $₫$ 106-112. . . . . . . . . . . 147

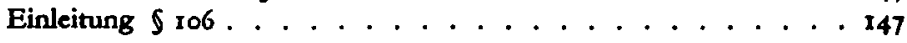

Erstes Lehrstück: Von der Wiedergeburt $\$ 107-109 . . . . . . ~ I 50$

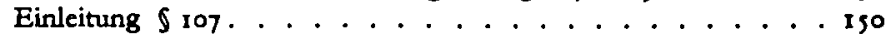

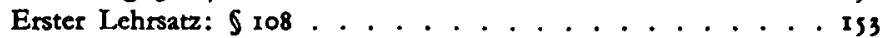

Zweiter Lehrsatz: $\$ 109 \ldots \ldots . . . \ldots$. . . . . . . . . . . .

Zweites Lehrstück: Von der Heiligung $₫$ 110-112 . . . . . I82

Einleitung $₫ 110 \ldots \ldots \ldots \ldots$............ 182

Erster Lehrsatz: $\S_{111} \ldots \ldots \ldots$

Zweiter Lehrsatz: $\S_{112} \ldots \ldots . . \ldots$. . . . . . I98 
Zweiter Abschnitt: Von der Beschaffenheit der Welt bezüglich auf die Erlösung $\int_{113}-163 \ldots 207$

Einleitung $\S_{113.114} \ldots \ldots \ldots \ldots \ldots$

Erstes Haupestuck: Von dem Entstehen der Kirche \$115-125 . . 215 Einleitung $\$ 11$ g. $116 \ldots . . . . . . . . .215$

Erstes Lehrstück: Von der Erwählung \$117-120 . . . . . 220

Einleitung $\$ 117.118 \ldots \ldots 20$

Erster Lehrsatz: \$119 . . . . . . . . . . . . . . 23I

Zweiter Lehrsatz: $\oint_{120} \ldots \ldots . . . \ldots 238$

Zusatz .................. 238

Zweites Lehrstück : Von der Mitteilung des heiligen Geistes $\$ 121-125248$ Einleitung $\ 121,122 \ldots \ldots . . \ldots . . . \ldots 248$

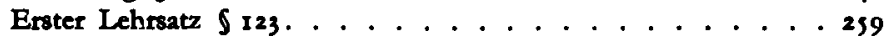

Zweiter Lehrsatz $\$ 124 \ldots \ldots . . . . . . . . . . .264$

Dritter Lehrsatz $\$ 125 \ldots \ldots 270$

Zweiles Hauplstuck: Von dem Bestehen der Kirche in ihrem Zusam-

mensein mit der Welt $\$ 126-156 \ldots 274$

Einleitung \$126................. 274

Erste Hālfte: Die wesentlichen und unveränderlichen Grundzüge der Kirche $\$ 127-147 \ldots \ldots . \ldots 278$ Einleitung $\$ 127 \ldots \ldots . . \ldots . . . . . . .278$

Erstes Lehrstück: Von der heiligen Schrift $\oint_{128-132} \ldots . .284$ Einleitung $₫$ 128. $129 \ldots \ldots 284$ Erster Lehrsatz: $\oint_{130} \ldots \ldots . . . \ldots . . . . . .291$ Zweiter Lehrsatz $\$ 131 \ldots . . . . . . . . . .299$

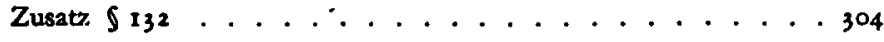

Zweites Lehrstück : Vom Dienst am göttlichen Wort \$133-135 . . 308 Einleitung $\$ 133 \ldots \ldots \ldots 12$

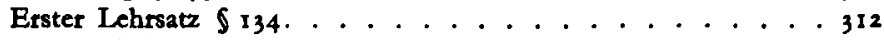

Zweiter Lehrsatz $\$ 135 . . . . . . . . . . .315$

VII Drittes Lehrstück: Von der Taufe $\$ 136-138 \ldots \ldots$. . . . . 318

Einleitung $\$ 136 \ldots \ldots . \ldots \ldots 18$

Erster Lehrsatz $\& 137 \ldots \ldots 326$

Zweiter Lehrsatz $\ 138 \ldots . . . . . . . . . . .335$

Viertes Lehrstrick: Vom Abendmahl $\oint_{139-142}$. . . . . 340

Einleitung $\$ 139-140 \ldots . . . . . . . .340$

Erster Lehrsatz \$14t. . . . . . . . . . . . . . . . . 3s\$

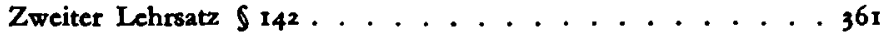

Anhang zum dritten und vierten Lehrstück: $143 . \ldots . . .363$

Fünftes Lehrstück: Vom Amt der Schlüssel $\$ 144.145$. . . . . 367

Einleitung \$ $144 \ldots \ldots . \ldots \ldots 67$

Lehrsatz $\$ 145 . \ldots . . . \ldots . . . . .369$ 
Sechstes Lehrstück: Vom Gebet im Namen Jesu $\$ 146.147$. . 376 Einleitung $\$ 146 \ldots \ldots . \ldots . \ldots 376$

Lehrsatz \$ 147 . . . . . . . . . . . . . . . . . 379

Zweite Hälfte: Das Wandelbare, was der Kirche zukommt vermöge ihres Zusammenseins mit der Welt $\$ 148-156 \ldots . . . .384$

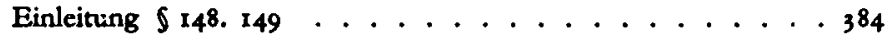

Erstes Lehrstück: Von der Mehrheit der sichtbaren Kirche in bezug auf die Einheit der unsichtbaren $\$ 1$ 50-152 . . . . . 391

Einleitung \Is0............... . 391

Erstex Lehrsatz \1SI. . . . . . . . . . . . . . 393 IX

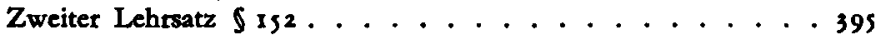

Zweites Lehrstück: Von der Irrtumsfähigkeit der sichtbaren Kirche in bezug auf die Untrüglichkeit der unsichtbaren $\$ 153-1$ ss . . 398

Einleitung $₫ \times s 3 \ldots \ldots 398$

Erster Lehrsatz \$ $154 . \ldots . . . . . . . . .400$

Zweiter Lehrsatz $\$ 155 . \ldots \ldots$. . . . . . . . . 402

Zusatz zu beiden Lehrstücken $₫ 156 \ldots$. . . . . . . . 404

Drittes Hauptstick: Von der Vollendung der Kirche $\int 157-163 .+408$

Einleitung \$157-159 ............. 408

Erstes prophetisches Lehrstück: Von der Wiederkunft Christi $\$ 160 . 421

Zweites prophetisches Lehrstück: Von der Auferstehung des Fleisches

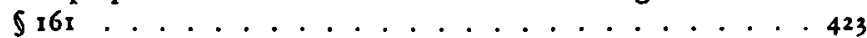

Drittes prophetisches Lehrstück: Vom jüngsten Gericht 162 . . 429

Viertes prophetisches Lehrstück: Von der ewigen Seligkeit $\$ 163 .+433$

Zusatz zu den prophetischen Lehrstücken . . . . . . . . . 439

Dritter Abschnitt: Von den göttlichen Eigenschaften, welche

sich auf die Erlösung beziehen $\$ 164-I 69 . . . . . . ~ .44 I$

Einleitung $\$ 164-165 \ldots . \ldots 441$

Erstes Lehrstück: Von der göttlichen Liebe $\$ 166.167 . \ldots .446 \times$

Einleitung $\$ 166 \ldots \ldots . \ldots . \ldots 446$

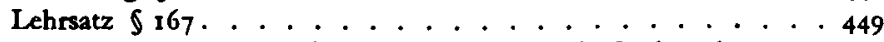

Zweites Lehrstück: Yon der göttlichen Weisheit \$168. I69 . . 45I

Einleitung $\ 168 \ldots \ldots . \ldots . \ldots 45$

Lehrsatz $\$ 169 . \ldots . . . . . . . . .455$

Schluß: Von der göttlichen Dreiheit $₫ 170-172 \ldots . . .458$

\section{Anhang des Herausgebers}

Vergleichendes Register der Seitenzahlen der 2.-7. Auflage . . 476 Synopse der Leitsätze der I. und 2. Auflage mit bisher unveröffentlichten Zusätzen aus Schleiermachers Kollegheft . . 497

Verzeichnis der Personen . . . . . . . . . . . . . . . 964

Verzeichnis der Bibelstellen............... . 566

Verzeichnis der wichtigsten Stichwörter ......... 572 
